\title{
Sleep apnea, apolipoprotein epsilon 4 allele, and TBI: Mechanism for cognitive dysfunction and development of dementia
}

\author{
Ruth O’Hara, PhD; ${ }^{1-2^{*}}$ Avinoam Luzon, BS; ${ }^{2}$ Jeffrey Hubbard, BA; ${ }^{1-2}$ Jamie M. Zeitzer, PhD $^{1-2}$ \\ ${ }^{1}$ Sierra-Pacific Mental Illness Research, Education, and Clinical Center, Department of Veterans Affairs Palo Alto \\ Health Care System, Palo Alto, CA; ${ }^{2}$ Department of Psychiatry and Behavioral Sciences, Stanford University School of \\ Medicine, Stanford University, Stanford, CA
}

\begin{abstract}
Sleep apnea is prevalent among patients with traumatic brain injuries (TBIs), and initial studies suggest it is associated with cognitive impairments in these patients. Recent studies found that the apolipoprotein epsilon 4 (APOE epsilon 4) allele increases the risk for sleep disordered breathing, particularly sleep apnea. The APOE epsilon 4 allele is associated with cognitive decline and the development of dementia in the general population as well as in patients with TBI. These findings raise the question of whether patients with TBI who are APOE epsilon 4 allele carriers are more vulnerable to the negative effects of sleep apnea on their cognitive functioning. While few treatments are available for cognitive impairment, highly effective treatments are available for sleep apnea. Here we review these different lines of evidence, making a case that the interactive effects of sleep apnea and the APOE epsilon 4 allele represent an important mechanism by which patients with TBI may develop a range of cognitive and neurobehavioral impairments. Increased understanding of the relationships among sleep apnea, the APOE epsilon 4 allele, and cognition could improve our ability to ameliorate one significant source of cognitive impairment and risk for dementia associated with TBI.
\end{abstract}

Key words: Alzheimer disease, apolipoprotein epsilon 4, cognition, daytime sleepiness, dementia, mild cognitive impairment, obstructive sleep apnea, sleep apnea, sleep disordered breathing, traumatic brain injury.

\section{INTRODUCTION}

In recent years, there has been an increased focus on the prevalence and impact of sleep apnea in traumatic brain injury (TBI). Sleep apnea is well documented to negatively affect neurocognitive and neuropsychiatric functioning, including memory, attention, mood, and anxiety. Sleep apnea has recently been implicated in cognitive decline and risk for developing Alzheimer disease (AD). TBI has long been identified as a risk factor for the development of dementia, with some studies suggesting the risk is greater among those with the vulnerability factor for AD, apolipoprotein epsilon 4 (APOE \&4) allele. Herein we review the literature to date on sleep apnea in TBI and outline the evidence to suggest that these factors in combination with the presence of the APOE $\varepsilon 4$ may contribute significantly to cognitive dysfunction and the

\footnotetext{
Abbreviations: $\mathrm{AD}=$ Alzheimer disease, $\mathrm{APOE} \varepsilon 4=$ apolipoprotein epsilon 4, BiPAP = bilevel positive airway pressure, $\mathrm{CI}=$ confidence interval, CPAP = continuous positive airway pressure, $\mathrm{CSA}$ = central sleep apnea, $\mathrm{MCI}=$ mild cognitive impairment, $\mathrm{MinSaO}_{2}=$ minimum level of arterial oxygen saturation, NFT = neurofibrillary tangle, OR = odds ratio, OSA = obstructive sleep apnea, $\mathrm{RDI}=$ Respiratory Disturbance Index, $\mathrm{SDB}=$ sleep disordered breathing, SNP = single nucleotide polymorphism, TBI = traumatic brain injury, VA = Department of Veterans Affairs.

*Address all correspondence to Ruth O'Hara, PhD; Associate Director, Sierra-Pacific Mental Illness Research, Education, and Clinical Center (MIRECC), 151-Y, 3801 Miranda Avenue, Palo Alto, CA 94304; 650-736-2689; fax: 650-723-2795. Email: roh@stanford.edu

DOI:10.1682/JRRD.2008.10.0140
} 
development of dementia in these patients. Because the majority of sleep apnea patients are male and TBI is common among veterans because of combat and other factors, this work has significant importance for the Department of Veterans Affairs (VA).

\section{PREVALENCE OF SLEEP DISORDERED BREATHING IN TBI}

Recent evidence suggests an increased incidence of sleep disordered breathing (SDB) in TBI patients, with prevalence ranging from 25 [1] to 35 percent [2] compared with 4 to 9 percent in the general world population [3]. A recent investigation of sleep disorders in patients with TBI suggests as many as 50 to 70 percent of patients with TBI may suffer from some form of SDB [4]. These authors concluded that treatable sleep disorders, such as SDB, may be largely undiagnosed and untreated in the patient population with TBI. One initial investigation also suggests that SDB is associated with cognitive impairment in patients with TBI [3].

One of the most common forms of SDB is sleep apnea, of which obstructive sleep apnea (OSA) is by far the most prevalent. OSA is defined by frequent episodes of obstructed breathing during sleep. Specifically, it is characterized by sleep-related decreases (hypopneas) or pauses (apneas) in respiration with a characteristic association of snoring and excessive daytime sleepiness [56]. The diagnosis of OSA is confirmed when the patient presents with excessive daytime sleepiness and a Respiratory Disturbance Index (RDI) of $>5$ ((apneas + hypopneas) $\div$ total sleep time in hours) [7]. However, in general, referral for treatment is not considered for individuals exhibiting an RDI $<10$ but is routinely considered when an RDI is particularly elevated, even in the absence of daytime sleepiness. An obstructive apnea is defined as interruption of oronasal airflow of at least 10 seconds, corresponding to a complete obstruction of the upper airways (despite continuous chest and abdominal movements) associated with a decrease in oxygen saturation and/or arousals from sleep. An obstructive hypopnea is defined as at least 10 seconds of partial obstruction of the upper airways, resulting in an at least 50 percent decrease in oronasal airflow. These abnormal respiratory events are generally accompanied by heart rate variability and arousals from sleep, with frequent arousals being the most important factor in resultant excessive daytime sleepiness.

The prevalence of OSA is higher in men than in women [8]. OSA is found in all age groups, but despite a lifetime prevalence of between 4 and 9 percent in the general population, its prevalence increases with age [9]. In subjects between the ages of 30 and 65 years, 24 percent of men and 9 percent of women had OSA. Among subjects over 55 years, 30 to 60 percent have an RDI $>5$ [10]. In a population of community-dwelling older adults, 70 percent of men and 56 percent of women between the ages of 65 and 99 years have evidence of OSA with a criterion of RDI $>10$ [11].

Effective treatments are available for the alleviation of OSA. Treatment for mild cases includes weight loss, dental devices (which advance the tongue or mandible to increase posterior airway space), or upper airway surgery [12]. Additionally, positional therapies have been employed with success, with patients urged to sleep on their front or sides rather than their backs. The gold standard treatment, however, for moderate to severe cases of OSA is continuous or bilevel positive airway pressure (CPAP/BiPAP) [13]. Other upper airway surgical procedures can be used for particular cases with craniofacial abnormalities [14].

Sleep apnea can be readily characterized with objective measurements of breathing and electroencephalography during an overnight sleep episode. Yet many individuals who, on objective measures, have severely disturbed sleep due to sleep apnea often fail to realize that their sleep is disturbed; more often they describe impaired daytime alertness. This lack of awareness may be exacerbated in patients with severe TBI as these individuals may be unaware of their sleep problems because of cognitive or neurological deficits from their injury or a preoccupation with more immediate medical aspects of their injury. In general, those with severe TBI report fewer posttrauma symptoms than those with lesser injuries [15]. Those with mild trauma may be more aware of their sleep issues because of their capacity to be more acutely aware and sensitive to post-TBI neurological and neuropsychiatric changes. Indeed, disrupted sleep is a common complaint among patients with TBI [16]. Some of the observed sleep disruption in TBI may be due to sleep apnea. 
SLEEP APNEA, TBI, COGNITIVE FUNCTIONING, AND DEMENTIA

Sleep apnea is well documented as being associated with cognitive impairment. Impairments in attention memory, psychomotor function, and executive function have all been associated with sleep apnea [17-21]. One of the most consistent findings is that sleep apnea negatively affects delayed recall ability [22].

In a recent investigation of the effect of OSA on the cognitive functioning of patients with TBI, Wilde et al. found not only an increased incidence of OSA in patients with TBI but also a resultant decrease in the domains of delayed recall, attention, vigilance, and retention of both verbal and visual information in patients with both TBI and OSA [3]. Thirty-five patients with TBI were administered a comprehensive neuropsychological battery and assessed for OSA based on standard criteria with nocturnal polysomnography. Nineteen patients with TBI had both OSA and TBI and were compared with sixteen patients who had a TBI and no presence of OSA. Both groups were comparable with respect to age, education, severity of injury, time postinjury, and rating on the Glasgow Coma Scale. While the group with OSA and TBI had more attentional lapses, both groups performed comparably on measures of motor, visual construction, and attentional performance. However, patients with TBI with OSA performed significantly worse than the nonsleep-disordered patients with TBI on measures of both verbal and visual delayed recall.

Impaired delayed recall is a hallmark of typical and pathological cognitive aging and is a key feature of $\mathrm{AD}$. TBI itself is a noted risk factor for dementia. Dementia is an age-related progressive disorder characterized by loss of function in multiple cognitive domains that is severe enough to cause impairment in social and occupational functioning.

$\mathrm{AD}$ is the most common form of dementia, accounting for between 50 and 70 percent of all cases. It is a neurodegenerative disorder, characterized neuropathologically by widespread neuronal loss, presence of neurofibrillary tangles (NFTs), and deposits of amyloid beta in cerebral blood vessels and neuritic plaques. The medial-temporal lobes, hippocampus, and association cortex are preferentially affected, leading to a marked decline in cognitive functioning that is the hallmark feature of $\mathrm{AD}$ [23]. While individuals with dementia or $\mathrm{AD}$ experience cognitive impairment, not all cognitive impairment repre- sents a neurodegenerative disorder. One of the clearest findings to emerge from the field of cognitive aging is that performance on measures of memory and attention worsens with advancing age, which is regarded as part of the normal aging process. However, many older adults find these changes debilitating on a daily basis, interfering with activities ranging from medication compliance to productivity in the workplace. Recognition of ageassociated cognitive and memory decline that appeared to go beyond that typically associated with normal aging led to the classification of such problems as cognitive impairment or mild cognitive impairment (MCI), the presence of which can significantly increase the likelihood of developing AD or dementia. Indeed, the types of cognitive and behavioral deficits exhibited appear to be on a continuum of severity from those that hallmark AD and dementia to MCI.

\section{TBI AND RISK FOR DEMENTIA}

The suggestion that TBI contributes to the development of AD and dementia has a long past. As early as 1976, Khaime reported on three cases of AD that developed after brain injury [24]. Since then, numerous animal, experimental, and epidemiological studies have supported an association between TBI and dementia.

Animal studies suggest that TBI contributes to the development of core $\mathrm{AD}$ pathological features, including increased oxidative stress [25] and increased levels of amyloid beta [26-27]. Human postmortem studies have observed both amyloid beta deposition and tau pathology in patients with TBI [28-29]. Ikonomovic et al. conducted an immunohistochemical study of AD-related changes in temporal cortex resected from 18 patients with TBI (aged 18-64 years) treated surgically for severe TBI [30]. Diffuse cortical amyloid beta deposits were observed in one-third of subjects (aged 35-62 years) as early as 2 hours after injury, with only one individual (35 years of age) exhibiting "mature" dense-cored plaques. Tau-positive, NFT-like changes were detected in only two subjects, both of whom were more advanced in age and had no evidence of amyloid beta deposits. No sex differences were found among the three diagnostic groups. The authors suggested that amyloid beta plaques and early evidence of neuronal degenerative changes may develop rapidly after TBI, while fully developed NFTs may result from more chronic disease- or injury-related processes. 
The great majority of epidemiological investigations observe an association between TBI and the development of dementia [31-38], although some negative findings exist [39-41]. In one of the largest studies of veterans with TBI, Plassman et al. examined the association between early adult head injury, as documented by military hospital records, and dementia in late life [42]. Both moderate and severe head injury were associated with increased risk of AD. The results for mild head injury were inconclusive, but overall the findings suggested that moderate and severe head injuries in young men were associated with increased risk of AD and other dementias in later life.

Fleminger et al. [43] undertook a replication and extension of the meta-analysis of Mortimer et al. [44] by conducting a comprehensive and systematic search of electronic databases through August 2001. Fifteen casecontrol studies were identified that met the inclusion criteria, of which seven postdated Mortimer et al.'s study. Analysis of all 15 case-control studies was significant (odds ratio [OR] 1.58, 95\% confidence interval [CI] 1.21-2.06), indicating a history of head injury in those with AD. Also, the authors replicated the finding of Mortimer et al., who found that head injury is a risk factor for AD only in males (males: OR 2.29, 95\% CI 1.47-2.06; females: OR 0.91, 95\% CI 0.56-1.47) [43].

One proposed explanation for the sex difference in the risk of $\mathrm{AD}$ following head injury is the role of the female hormones, such as estrogen and progesterone. Animal models of stroke and TBI suggest that these hormones may confer a neuroprotective effect. Bramlett and Dietrich, for example, employed an animal model of TBI and found contusion volume was significantly smaller in adult female rats than in male and ovariectomized female rats [45]. Estrogen has been implicated as a potential protective factor in the development of $\mathrm{AD}$, although findings are mixed [46]. Whether females may be protected from $\mathrm{AD}$ following head injury because of the protective effects of female hormones remains to be more systematically investigated.

\section{TBI AND APOE $\varepsilon 4$ ALLELE: INCREASED VULNERABILITY FOR DEMENTIA}

Recent evidence points to a potential overlapping pathophysiological mechanism underlying the negative effect of both sleep apnea and TBI on cognitive function- ing. Several investigators suggest that the APOE $\varepsilon 4$ allele is a brain vulnerability marker and that APOE $\varepsilon 4$ allele carriers have a limited capacity to respond to physiological challenges and, hence, are more prone to cognitive deficits and poor recovery after insults to the nervous system [44,47-48]. The APOE $\varepsilon 4$ allele is a noted genetic risk factor for the development of $\mathrm{AD}$, and as many as 30 percent of individuals with MCI and cognitive impairment carry an APOE $\varepsilon 4$ allele [23]. APOE is a plasma protein that is involved in the transport of cholesterol and other lipids. The APOE protein is expressed by a gene on chromosome 19 with three allelic variants $(\varepsilon 2$, $\varepsilon 3, \varepsilon 4)$, resulting in six possible genotypes. It is present in senile plaques, NFTs, and cerebrovascular amyloid, the major neuropathological changes in $\mathrm{AD}$, and is implicated in the growth and regeneration of nerves during development and/or following injury. The APOE $\varepsilon 4$ allele thus appears to interact with other factors to increase vulnerability to cognitive and neurological problems, including dementia [44,47-50].

Presence of the APOE $\varepsilon 4$ allele has been documented to increase vulnerability to negative neurocognitive and functional outcomes in TBI. Hartman et al. found that APOE $\varepsilon 4$ allele influenced amyloid deposition but not cell loss after TBI in a mouse model of AD [27]. Tang et al. observed a tenfold increase in the risk of AD among those who were both APOE $\varepsilon 4$ carriers and had a history of TBI [51]. Head injury in non-APOE $\varepsilon 4$ carriers did not increase risk. Luukinen et al. found fall-related TBI to predict earlier onset of dementia, particularly in APOE $\varepsilon 4$ carriers [52], and Friedman et al. found APOE $\varepsilon 4$ carriers with TBI had significantly poorer functional outcome [53]. However, there are also many mixed findings with respect to the relationship between APOE genotype and TBI. Millar et al. found that although they observed late cognitive decline to occur after head injury, there was no clear relation to APOE genotype [54]. Replicating the finding of Guo et al., who found that TBI increased the risk for AD in non-APOE $\varepsilon 4$ carriers only [55], Jellinger et al. conducted the first retrospective autopsy study of $\mathrm{TBI}$, APOE $\varepsilon 4$ allele frequency, and $\mathrm{AD}$, in which they also found that severe TBI was a risk factor for the development of AD, most particularly in non-APOE $\varepsilon 4$ carriers [56-57]. But we should note that the sample size was very small in the work of Jellinger et al. and many of the negative studies generally focused upon the most severe cases of TBI. Mauri et al. obtained TBI history in 337 subjects with probable $\mathrm{AD}$ and 63 subjects with MCI 
[58]. A high frequency of the APOE $\varepsilon 4$ allele was detected in those with cognitive impairment $(40.5 \%$ in the $\mathrm{AD}$ and $11 \%$ in the MCI subgroups). O'Meara et al. suggested that the APOE $\varepsilon 4$ allele and TBI may represent independent risk factors for dementia [59].

In one of the most comprehensive investigations of this issue, Sundström et al. examined the relationship of mild levels of TBI and APOE $\varepsilon 4$ to risk for dementia using data from the Betula prospective population-based study of aging, memory, and health [60]. These data included information on 543 subjects, aged 40 to 85 years, who were free of dementia at baseline and who were followed up within a 5-year interval. Dementia was classified using Diagnostic and Statistical Manual of Mental Disorders-IV criteria, and information on previous head injury was obtained through screening of the participants' answers to health questionnaires at both baseline and at follow-up. The authors found that non-APOE $\varepsilon 4$ carriers with head injury did not have an increased risk of dementia. However, APOE $\varepsilon 4$ carriers had an increased risk for dementia $(\mathrm{OR}=$ 2.3), and those APOE $\varepsilon 4$ carriers who also had mild head injury had a statistically significant, higher risk of developing dementia $(\mathrm{OR}=5.2)$. Further, Isoniemi et al. examined the association of APOE genotype with longterm outcome in 61 patients with TBI [61]. The long-term outcome was evaluated with repeated neuropsychological testing and by applying various measures of everyday functioning and quality of life. After three decades, patients with TBI who were APOE $\varepsilon 4$ carriers showed a 63 percent decline in general cognitive level as measured by Mental Deterioration Battery Score compared with a 30 percent decline in patients who were carriers of the APOE $\varepsilon 3$ allele and a 5 percent improvement in patients who were carriers of the APOE $\varepsilon 2$ allele.

Overall, these findings suggest a significant additive negative effect of head trauma and presence of the APOE $\varepsilon 4$ allele on risk for dementia, such that the APOE $\varepsilon 4$ allele and TBI conspire to confer a greater risk than either the APOE $\varepsilon 4$ allele or TBI alone. However, this risk may increase according to the severity of the TBI and amount of time elapsed since the TBI occurred.

\section{SLEEP APNEA, TBI, AND APOE $\varepsilon 4$ ALLELE}

Presence of the APOE $\varepsilon 4$ allele has also been found to confer up to a twofold increased risk for OSA [62-63]. In a population-based probability sample of 791 middle- aged adults (mean \pm standard deviation age $=49 \pm$ 8 years, range $=32-68$ years), the probability of moderate-to-severe SDB was significantly higher in participants with the APOE $\varepsilon 4$ allele, independent of age, sex, body mass index, and race/ethnicity [63]. Although negative findings exist, most recently, Gottlieb et al. examined 1,775 subjects and confirmed an age-dependent association between the allele and sleep apnea [62].

Further, O'Hara et al. found that sleep apnea interacted with the APOE $\varepsilon 4$ allele to negatively affect memory and suggested that APOE $\varepsilon 4$ carriers with sleep apnea may be at increased risk for developing dementia [64]. This finding has recently been independently replicated by two groups: Gozal et al. found that children with OSA and poor cognitive performance were much more likely to be APOE $\varepsilon 4$ carriers [65], and similarly, Consentino et al. found that APOE $\varepsilon 4$ carriers who had presence of OSA had lower performance on a working memory task than those without apnea [66].

One recent investigation concentrated on several known single nucleotide polymorphisms (SNPs) within the APOE gene and its regulatory region in order to find associations with OSA status among children. They found that SNPs rs157580, rs405509, rs769455, and rs7412 all showed associations with OSA status, with age and body mass index as covariates. They concluded that polymorphisms in more than one locus in the APOE gene and its regulatory region are associated with OSA in children [67]. This finding lends itself to the conclusion that the interaction between TBI, OSA, and APOE genotype may be more complex than originally thought.

Sleep apnea-related cognitive impairment in TBI may reflect the hypoxia that accompanies sleep apnea events, with some additional impairment resulting from sleep fragmentation and daytime sleepiness [68]. Hypoxia is a defining feature of sleep apnea. Investigators have long suggested a model in which the neuronal injury resulting from hypoxia results in sleep apneaassociated cognitive impairment [68]. Hypoxic damage resulting from a broad range of disorders (e.g., brain injury, stroke, cardiac arrest) is well documented to negatively affect function and cognition, although the literature on the relationship between sleep apnea-related measures of hypoxia, such as minimum or average level of oxygen desaturation, and cognitive function is quite limited and the findings mixed [50,69-71]. In our own clinical investigation, we found that although average minimum level of arterial oxygen saturation $\left(\mathrm{MinSaO}_{2}\right)$ 
displayed a nonsignificant tendency to negatively interact with the APOE $\varepsilon 4$ allele to affect memory, the actual number of respiratory events was most strongly associated with impaired cognition [50]. Although most studies of this issue employ a single or average measure of oxygen desaturation, interaction of duration, frequency, and level of hypoxia, rather than $\mathrm{MinSaO}_{2}$ alone, may exert the greatest clinical impact.

An alternate explanation is that apnea/hypopneaassociated sleep fragmentation, rather than hypoxia per se, negatively affects cognition. Individuals with neuronal loss due to a TBI may be particularly vulnerable to the hypoxic events that accompany sleep apnea, as well as to the behavioral outcomes such as cognitive impairment and depression that have been consistently associated with the presence of sleep apnea [57,72]. A recent investigation by Chang et al. found that brain tissue hypoxia is common among patients with TBI; however, no measurement of apnea was included in this finding [73]. Further studies are needed to determine the hypoxic effect of sleep apnea in patients with TBI.

Animal studies suggest that the APOE $\varepsilon 4$ allele increases neuronal vulnerability to oxidative stress [74]. The suggestion that APOE $\varepsilon 4$ exacerbates sleep apneaassociated cognitive impairment by reducing the brain's response to the hypoxic events experienced during apnea is consistent with observations that hypoxia and APOE $\varepsilon 4$ status impact the hippocampus. Hypoxia has negative effects on neuronal integrity in the hippocampus [75-76]. These same hippocampal regions, which subserve delayed recall, also appear vulnerable to deleterious effects of the APOE $\varepsilon 4$ allele [77-79]. Furthermore, our preliminary data found a negative association between even mild levels of sleep apnea and impaired delayed recall only in those with the APOE $\varepsilon 4$ allele. Further, the common link between TBI and sleep apnea may be the resultant hypoxic effects exerted on brain tissue by both of these conditions, with presence of the APOE e4 allele further mitigating against an effective neuronal recovery response to the hypoxia.

Increased understanding of the relationships among sleep apnea, APOE genotype, and hypoxia may provide significant insight into the molecular mechanisms that initiate critical pathological cascades in TBI. Further, the effective treatments available for sleep apnea may go a long way to improving the prognosis for patients with TBI not only in terms of the pathophysiology associated with the disorder but also in terms of improving the nega- tive comorbid cognitive and psychiatric symptoms that are so prevalent in TBI.

\section{Treatment of Sleep Apnea in TBI}

Sleep hygiene provides subjects with basic education about daily behaviors, environmental conditions, and other sleep-related factors that have the potential to interfere with or support good sleep [80-81]. With respect to sleep apnea, treatment studies indicate that CPAP/BiPAP can be very effective in reducing not only sleep apnea events but also the associated cognitive and affective sequelae $[64,72]$, although compliance can be difficult for all patients. To date, no systematic studies have been conducted on CPAP/BiPAP use in patients with TBI. Given the effectiveness of this treatment approach, it may be particularly valuable for alleviating a range of behavioral and psychiatric symptoms in patients with TBI with comorbid sleep apnea.

\section{Sleep Apnea in TBI: Vulnerability Factor or Mechanism for Impairment}

Patients who present with OSA may actually be at greater risk for TBI. OSA is well documented to cause sleepiness, which increases the likelihood of having an accident while driving [82]. Motor vehicle accidents may result in TBI or other bodily damage. Sleepiness is a factor in 42 to 54 percent of motor vehicle collisions [2]. Evidence exists that the presence of OSA is associated with increased risk for traffic accidents [83-84]. While there may be some dual causality of TBI and OSA, the direction of the relationship is still not clearly defined. In the United States, 80,000 people become permanently disabled from TBI as a result of motor vehicle crashes, falls, acts of violence, and sports incidents each year [85].

Alternatively, sleep apnea in TBI may occur secondary to the brain injury itself. In contrast to OSA, central sleep apnea (CSA) is defined as a lack of airflow accompanied by a lack of respiratory effort, reflecting impairments in brain areas controlling breathing. The important difference is that while in OSA, there is periodic apnea and asphyxia from upper airway obstruction or collapse in the pharynx, there is continued respiratory effort. CSA, then, may be indicative of more severe TBI or brain malformation [86].

In a recent study, patients who showed progression into white matter disease assessed by longitudinal magnetic resonance imaging scans were significantly more likely to have an increased number of central rather than 
obstructive apneas. This result led the investigators to conclude that there is a causal pathway in which CSA contributes to the progression of white matter disease [86]. However, there may be a dual causality, in that it may be the presence of white matter disease that contributes to CSA, which then in turn exacerbates the already present white matter disease.

Webster et al. found that, in a relatively small study, 10 of 28 patients with TBI had sleep apnea and that the majority of these events were central apneas rather than obstructive apneas [87]. Normally, sleep apnea events are about 90 percent obstructive and only 10 percent central in nature [88]. Although the rate of sleep apnea was significantly higher than would be predicted of population norms, there was no correlation between presence of significant sleep apnea and severity of TBI.

\section{Sleep Apnea in TBI: Relevance to Veterans}

Several investigators have suggested that sleep apnea is highly prevalent in veteran populations, likely reflecting the fact that there is increased prevalence of sleep apnea with age and that this disorder is far more common among men [89-90]. However, in a recent investigation of more than 4,060,504 health records of veterans, Sharafkhaneh et al. found very similar prevalence rates of sleep apnea, namely 2.91 percent, to general population rates [91]. The authors raised the concern that this may reflect the fact that sleep apnea may be underdiagnosed in the veteran population. Indeed, Mustafa et al. used a self-report questionnaire to identify chronic symptoms of sleep disorders among patients in VA medical centers and found that with a mean age of 62.5 years, 47.4 percent met high-risk criteria for sleep apnea [92]. Further, Sharafkhaneh et al. found that those veterans with sleep apnea had far higher rates of psychiatric and medical comorbidity, including posttraumatic stress disorder, anxiety, and dementia, than those without this disorder [91].

Not only is sleep apnea more prevalent in men but the negative relationship of TBI to risk for dementia also seems to be exacerbated in men. Van Duijn et al. conducted a population-based case-control study of the association between head trauma and AD [93]. They compared 198 patients with clinically diagnosed early onset AD and 198 age- and sex-matched population controls. Following adjustment for sex, age, family history of dementia, and education, the OR of a history of head trauma (with loss of consciousness) was 1.6 (95\% CI 0.8-3.4). However, the OR for men was 2.5 (95\% CI 0.9-
7.0), compared with 0.9 (95\% CI 0.3-2.8) for women. Thus, male veterans may be at increased risk not only for sleep apnea itself but also for negative neurological and neuropsychiatric consequences of this disorder.

\section{SUMMARY AND CONCLUSIONS}

Increased understanding of the relationships between sleep apnea, APOE $\varepsilon 4$ allele, and cognition could lead to improved therapeutic approaches to the cognitive impairment associated with TBI, as well as increasing our understanding of the pathophysiological mechanisms underlying the negative consequences of TBI.

Recovery from a TBI is often lengthy and difficult, and this recovery process may be hampered by the presence of a comorbid sleep disorder. Disruption of normal sleep by sleep apnea can also exacerbate other neuropsychiatric sequelae of TBI, potentially leading to long-term consequences and a decrement in overall quality of life. Sleep apnea is very prevalent in the veteran population and can be treated with one of the well-established and effective treatment approaches, such as CPAP/BiPAP, positional therapies, surgery, or weight loss. More systematic research is necessary in order to provide a foundation for an evidence-based medical approach to the treatment of sleep in the context of TBI. If, as the literature suggests, the APOE $\varepsilon 4$ allele is associated with an increased risk for sleep apnea, then sleep apnea may be responsible for, i.e., mediate, any negative relationship between the APOE $\varepsilon 4$ allele and cognitive impairment in TBI (Figure 1). Alternatively, any negative relationship between sleep apnea and cognitive function in TBI may reflect the increased vulnerability of APOE $\varepsilon 4$ carriers to the neurological effects of sleep apnea, specifically apnea-associated hypoxia (Figure 2). As such, the APOE $\varepsilon 4$ allele would moderate the relationship between sleep apnea and cognition in TBI. In this case, treatments for sleep apnea might target only APOE $\varepsilon 4$ carriers. Of course, it is important to note that if there is a negative additive effect of hypoxia and APOE $\varepsilon 4$ on the risk for dementia among patients with TBI, sleep apnea is not the only disorder that can result in hypoxia. Conditions such as chronic obstructive pulmonary disorder, pulmonary fibrosis, and asthma, for example, can all result in hypoxia, such that presence of any of these disorders might increase the risk for dementia and cognitive decline in patients with TBI. Another viable possibility is 


\section{Mediator Model}

OSA Mediates Negative Association of APOE $\varepsilon 4$ on Cognitive Function in TBI

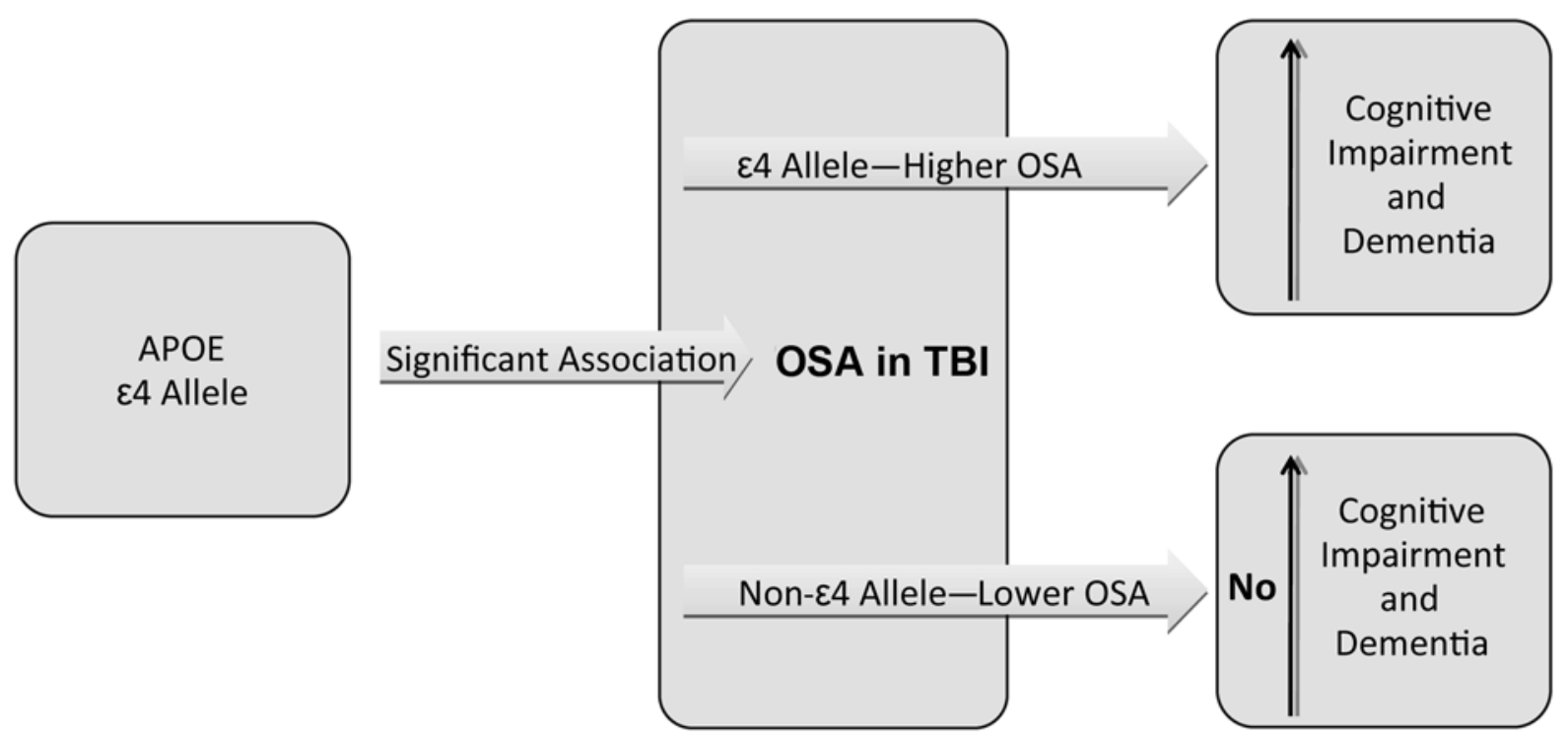

Figure 1.

Mediator model: Proposed model for obstructive sleep apnea (OSA) mediating negative association of apolipoprotein epsilon 4 (APOE $\varepsilon 4$ ) on cognitive function in traumatic brain injury (TBI) patients. In this model, a significant association is found between APOE $\varepsilon 4$ allele and OSA and OSA is responsible for observed increase in cognitive impairment and dementia in those with APOE $\varepsilon 4$ allele; those without APOE $\varepsilon 4$ allele display decreased OSA and no increase in cognitive impairment and dementia.

that apnea/hypopnea-associated sleep fragmentation, rather than hypoxia per se, negatively affects neurological and neuropsychological outcomes. Future studies are required to investigate this possibility.

Larger longitudinal studies are required to clarify these issues-whether the APOE $\varepsilon 4$ allele increases vulnerability to the negative effect of SDB on cognition in patients with TBI or whether the relationship between APOE $\varepsilon 4$ and cognition is in fact due to the higher prevalence of SDB in these patients. Further, such longitudinal prospective studies, with full polysomnography, are required to address whether the relationship between sleep apnea and risk for dementia and cognitive decline in patients with TBI is mediated by the sleep-apnea associated hypoxia or sleep fragmentation or moderated by characteristics of the TBI itself, such as severity and duration since onset. Such relationships could also be examined within the context of treatment trials of CPAP, for example, for sleep apnea in veterans with TBI.
Overall, however, the evidence suggests that patients with TBI have an increased prevalence of sleep apnea. Considering the high carrier frequency of the APOE $\varepsilon 4$ allele in the general population (25\%), this polymorphism may account for a very substantial portion of the attributable risk for sleep apnea. Given that the APOE $\varepsilon 4$ allele is also associated with increased risk for cognitive impairment and decline, sleep apnea and the APOE $\varepsilon 4$ allele may conspire to both exacerbate cognitive impairment and accelerate the cognitive decline in patients with TBI. The risk for sleep apnea is greater in men. Given that the majority of veterans are men who are also at increased risk for TBIs, any relationship between sleep apnea and cognitive dysfunction in this patient group is of particular relevance and importance for the VA. While there are few effective therapeutic approaches for cognitive impairment, effective treatments for sleep apnea are available, including weight loss, dental devices, upper airway surgeries, and CPAP/BiPAP. Increased understanding of the 


\section{Moderator Model}

\section{APOE $\& 4$ Moderates Negative Association of OSA on Cognitive Function in TBI}

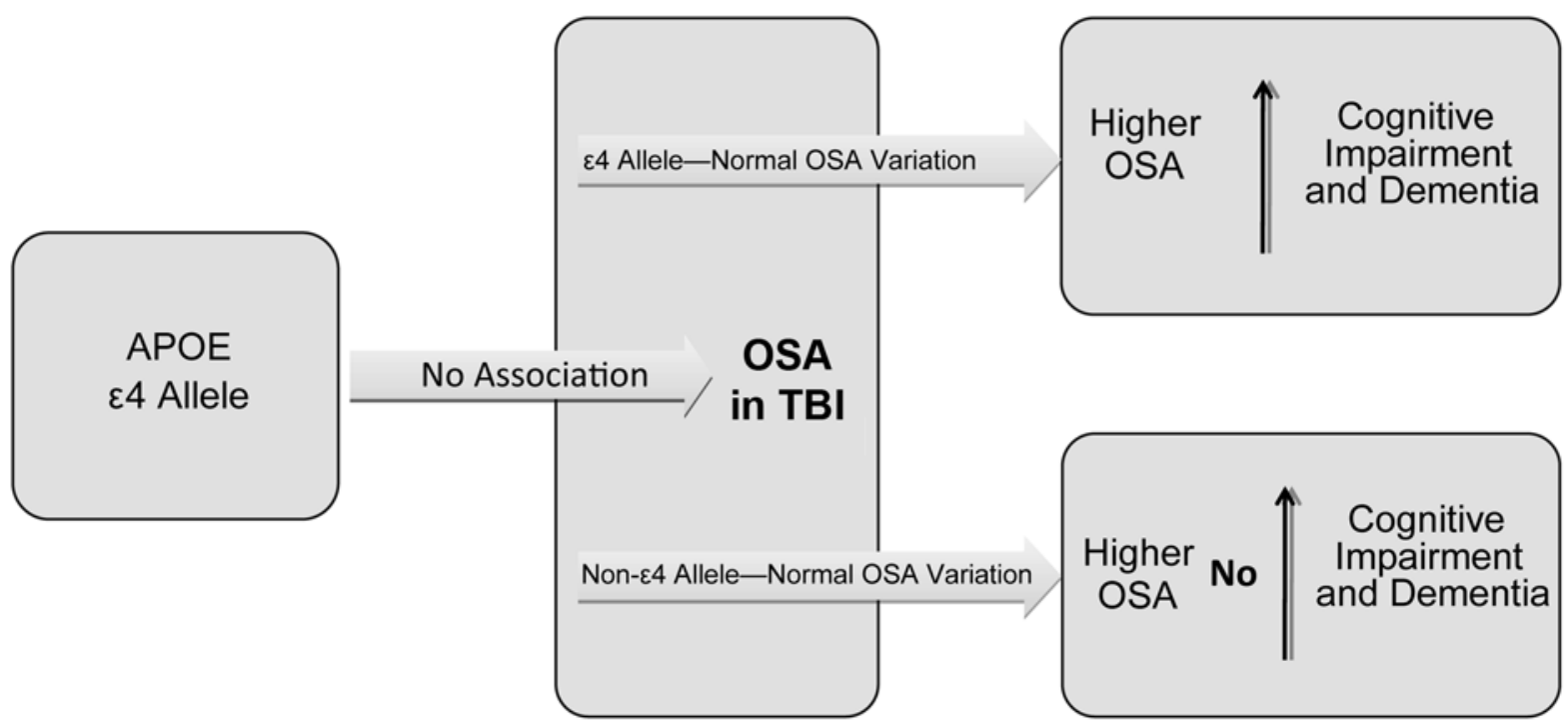

Figure 2.

Moderator model: Proposed model for apolipoprotein epsilon 4 (APOE $\varepsilon 4$ ) moderating negative effect of obstructive sleep apnea (OSA) on cognitive function in traumatic brain injury (TBI) patients. In this model, no significant association is found between APOE $\varepsilon 4$ allele and OSA and the negative relationship between higher OSA and cognitive impairment and dementia reflects increased vulnerability of APOE $\varepsilon 4$ carriers to effects of OSA.

relationships among sleep apnea, APOE $\varepsilon 4$, and cognition could lead to improved therapeutic approaches to the cognitive impairment associated with TBI, as well as increase our understanding of the pathophysiological mechanisms underlying the negative consequences of TBI.

\section{ACKNOWLEDGMENTS}

\section{Author Contributions:}

Study concept and design: R. O’Hara.

Acquisition of data: R. O’Hara, A. Luzon, J. Hubbard.

Analysis and interpretation of data: R. O’Hara, A. Luzon, J. Hubbard, J. M. Zeitzer.

Drafting of manuscript: R. O’Hara, A. Luzon, J. Hubbard,

J. M. Zeitzer.

Critical revision of manuscript for important intellectual content:

R. O’Hara, A. Luzon, J. Hubbard, J. M. Zeitzer.

Statistical analysis: R. O’Hara.

Obtained funding: R. O’Hara.

Administrative, technical, or material support: R. O’Hara, A. Luzon, J. Hubbard.

Study supervision: R. O’Hara.
Financial Disclosures: The authors have declared that no competing interests exist.

Funding/Support: This work was supported in part by the VA SierraPacific Mental Illness Research, Education, and Clinical Center (MIRECC); the Stanford/VA Alzheimer's Research Center; the National Institutes of Health (grants MH 070886, AG 18784, and AG 17824); and the State of California Department of Health Services (grant 06-55310).

\section{REFERENCES}

1. Castriotta RJ, Wilde MC, Lai JM, Atanasov S, Masel BE, Kuna ST. Prevalence and consequences of sleep disorders in traumatic brain injury. J Clin Sleep Med. 2007;3(4):349-56. [PMID: 17694722]

2. Webster JB, Bell KR, Hussey JD, Natale TK, Lakshminarayan S. Sleep apnea in adults with traumatic brain injury: A preliminary investigation. Arch Phys Med Rehabil. 2001;82(3):316-21. [PMID: 11245752] DOI:10.1053/apmr.2001.20840 
3. Wilde MC, Castriotta RJ, Lai JM, Atanasova S, Masel BE, Kuna ST. Cognitive impairment in patients with traumatic brain injury and obstructive sleep apnea. Arch Phys Med Rehabil. 2007;88(10):1284-88. [PMID: 17908570] DOI:10.1016/j.apmr.2007.07.012

4. Castriotta RJ, Lai JM. Sleep disorders associated with traumatic brain injury. Arch Phys Med Rehabil. 2001;82(10): 1403-6. [PMID: 11588744] DOI:10.1053/apmr.2001.26081

5. Lee HB, Lyketsos CG, Rao V. Pharmacological management of the psychiatric aspects of traumatic brain injury. Int Rev Psychiatry. 2003;15(4):359-70. [PMID: 15276957] DOI:10.1080/09540260310001606746

6. Gastaut H, Tassinari CA, Duron B. [Polygraphic study of diurnal and nocturnal (hypnic and respiratory) episodal manifestations of Pickwick syndrome]. Rev Neurol (Paris). 1965;112(6):568-79. French. [PMID: 5856212]

7. Guilleminault C, Tilkian A, Dement WC. The sleep apnea syndromes. Annu Rev Med. 1976;27:465-84.

[PMID: 180875] DOI:10.1146/annurev.me.27.020176.002341

8. Sleep-related breathing disorders in adults: Recommendations for syndrome definition and measurement techniques in clinical research. The Report of an American Academy of Sleep Medicine Task Force. Sleep. 1999;22(5):667-89. [PMID: 10450601]

9. Krieger J, Mangin P, Kurtz D. [Respiratory changes during sleep in healthy elderly subjects]. Rev Electroencephalogr Neurophysiol Clin. 1980;10(2):177-85. French. [PMID: 7209080] DOI:10.1016/S0370-4475(80)80051-7

10. Carskadon MA, Dement WC. Respiration during sleep in the aged human. J Gerontol. 1981;36(4):420-23.

[PMID: 7252072]

11. Ancoli-Israel S. Epidemiology of sleep disorders. Clin Geriatr Med. 1989;5(2):347-62. [PMID: 2665916]

12. Victor LD. Obstructive sleep apnea. Am Fam Physician. 1999;60(8):2279-86. [PMID: 10593319]

13. Sullivan CE, Issa FG, Berthon-Jones M, Eves L. Reversal of obstructive sleep apnoea by continuous positive airway pressure applied through the nares. Lancet. 1981;1(8225): 862-65. [PMID: 6112294] DOI:10.1016/S0140-6736(81)92140-1

14. Ancoli-Israel S, Kripke DF, Klauber MR, Mason WJ, Fell $\mathrm{R}$, Kaplan O. Sleep-disordered breathing in communitydwelling elderly. Sleep. 1991;14(6):486-95.

[PMID: 1798880]

15. Verdi FJ Jr, Slanzi GL, Cohen SR, Powell R. Use of the Branemark implant in the cleft palate patient. Cleft Palate Craniofac J. 1991;28(3):301-303. [PMID: 1911819] DOI:10.1597/1545-1569(1991)028<0325:UOTBII >2.3.CO;2
16. Parcell DL, Ponsford JL, Rajaratnam SM, Redman JR. Self-reported changes to nighttime sleep after traumatic brain injury. Arch Phys Med Rehabil. 2006;87(2):278-85. [PMID: 16442985]

DOI:10.1016/j.apmr.2005.10.024

17. Trudel TM, Tyron WW, Purdum CM. Awareness of disability and long-term outcome after traumatic brain injury. Rehabil Psychol. 1998;43(4):267-81. DOI:10.1037/0090-5550.43.4.267

18. Cohen-Zion M, Stepnowsky C, Marler PD, Shochat T, Kripke DF, Ancoli-Israel S. Changes in cognitive function associated with sleep disordered breathing in older people. J Am Geriatr Soc. 2001;49(12):1622-27. [PMID: 11843994] DOI:10.1111/j.1532-5415.2001.49270.x

19. Aloia MS, Ilniczky N, Di Dio P, Perlis ML, Greenblatt DW, Giles DE. Neuropsychological changes and treatment compliance in older adults with sleep apnea. J Psychosom Res. 2003;54(1):71-76. [PMID: 12505557]

DOI:10.1016/S0022-3999(02)00548-2

20. Naegele B, Pepin JL, Levy P, Bonnet C, Pellat J, Feuerstein C. Cognitive executive dysfunction in patients with obstructive sleep apnea syndrome (OSAS) after CPAP treatment. Sleep. 1998;21(4):392-97. [PMID: 9646384]

21. Redline S, Strauss ME, Adams N, Winters M, Roebuck T, Spry K, Rosenberg C, Adams K. Neuropsychological function in mild sleep-disordered breathing. Sleep. 1997;20(2): 160-67. [PMID: 9143077]

22. Décary A, Rouleau I, Montplaisir J. Cognitive deficits associated with sleep apnea syndrome: A proposed neuropsychological test battery. Sleep. 2000;23(3):369-81. [PMID: 10811381]

23. O'Hara R, Yesavage JA, Derouesne C. Therapeutic approaches to age-associated neurocognitive disorders. Dialogues Clin Neurosci. 2001;3(3):191-213.

24. Khaime TsB. [Role of craniocerebral trauma in the development of Alzheimer's disease]. Zh Nevropatol Psikhiatr Im S S Korsakova. 1976;76(7):1028-32. Russian. [PMID: 961285]

25. Uryu K, Laurer H, McIntosh T, Practicò D, Martinez D, Leight S, Lee VM, Trojanowski JQ. Repetitive mild brain trauma accelerates Abeta deposition, lipid peroxidation, and cognitive impairment in a transgenic mouse model of Alzheimer amyloidosis. J Neurosci. 2002;22(2):446-54. [PMID: 11784789]

26. Blasko I, Beer R, Bigl M, Apelt J, Franz G, Rudzki D, Ransmayr G, Kampfl A, Schliebs R. Experimental traumatic brain injury in rats stimulates the expression, production and activity of Alzheimer's disease beta-secretase (BACE-1). J Neural Transm. 2004;111(4):523-36.

[PMID: 15057522] DOI:10.1007/s00702-003-0095-6 
27. Hartman RE, Laurer H, Longhi L, Bales KR, Paul SM, McIntosh TK, Holtzman DM. Apolipoprotein E4 influences amyloid deposition but not cell loss after traumatic brain injury in a mouse model of Alzheimer's disease. J Neurosci. 2002;22(23):10083-87. [PMID: 12451108]

28. Jellinger KA. Traumatic brain injury as a risk factor for Alzheimer's disease. J Neurol Neurosurg Psychiatry. 2004; 75(3):511-12. [PMID: 14966185]

29. Szczygielski J, Mautes A, Steudel WI, Falkai P, Bayer TA, Wirths O. Traumatic brain injury: Cause or risk of Alzheimer's disease? A review of experimental studies. J Neural Transm. 2005;112(11):1547-64. [PMID: 15959838] DOI:10.1007/s00702-005-0326-0

30. Ikonomovic MD, Abrahamson EE, Isanski BA, Wuu J, Mufson EJ, DeKosky ST. Superior frontal cortex cholinergic axon density in mild cognitive impairment and early Alzheimer disease. Arch Neurol. 2007;64(9):1312-17. [PMID: 17846271] DOI:10.1001/archneur.64.9.1312

31. Amaducci LA, Rocca WA, Schoenberg BS. Origin of the distinction between Alzheimer's disease and senile dementia: How history can clarify nosology. Neurology. 1986; 36(11):1497-99. [PMID: 3531918]

32. Gottlieb S. Head injury doubles the risk of Alzheimer's disease. Brit Med J. 2000;321:1100.

33. Graves AB, White E, Koepsell TD, Reifler BV, Van Belle G, Larson EB, Raskind M. The association between head trauma and Alzheimer's disease. Am J Epidemiol. 1990; 131(3):491-501. [PMID: 2405648]

34. Jellinger KA, Paulus W, Wrocklage C, Litvan I. Effects of closed traumatic brain injury and genetic factors on the development of Alzheimer's disease. Eur J Neurol. 2001; 8(6):707-10. [PMID: 11784357] DOI:10.1046/j.1468-1331.2001.00322.x

35. Lye TC, Shores EA. Traumatic brain injury as a risk factor for Alzheimer's disease: A review. Neuropsychol Rev. 2000;10(2):115-29. [PMID: 10937919] DOI:10.1023/A:1009068804787

36. Mortimer JA, French LR, Hutton JT, Schuman LM. Head injury as a risk factor for Alzheimer's disease. Neurology. 1985;35(2):264-67. [PMID: 3969219]

37. O’Meara ES, Kukull WA, Sheppard L, Bowen JD, McCormick WC, Teri L, Pfanschmidt M, Thompson JD, Schellenberg GD, Larson EB. Head injury and risk of Alzheimer's disease by apolipoprotein E genotype. Am J Epidemiol. 1997;146(5):373-84. [PMID: 9290497]

38. Schofield PW, Tang M, Marder K, Bell K, Dooneief G, Chun M, Sano M, Stern Y, Mayeux R. Alzheimer's disease after remote head injury: An incidence study. J Neurol Neurosurg Psychiatry. 1997;62(2):119-24.

[PMID: 9048710]

DOI:10.1136/jnnp.62.2.119
39. Broe GA, Henderson AS, Creasey H, McCusker E, Korten AE, Jorm AF, Longley W, Anthony JC. A case-control study of Alzheimer's disease in Australia. Neurology. 1990; 40(11):1698-1707. [PMID: 2146525]

40. Chandra V, Kokmen E, Schoenberg BS, Beard CM. Head trauma with loss of consciousness as a risk factor for Alzheimer's disease. Neurology. 1989;39(12):1576-78. [PMID: 2586772]

41. Mehta KM, Ott A, Kalmijn S, Slooter AJ, Van Duijn CM, Hofman A, Breteler MM. Head trauma and risk of dementia and Alzheimer's disease: The Rotterdam Study. Neurology. 1999;53(9):1959-62. [PMID: 10599765]

42. Plassman BL, Havlik RJ, Steffens DC, Helms MJ, Newman TN, Drosdick D, Phillips C, Gau BA, Welsh-Bohmer KA, Burke JR, Guralnik JM, Breitner JC. Documented head injury in early adulthood and risk of Alzheimer's disease and other dementias. Neurology. 2000;55(8):1158-66. [PMID: 11071494]

43. Fleminger S, Oliver DL, Lovestone S, Rabe-Hesketh S, Giora A. Head injury as a risk factor for Alzheimer's disease: The evidence 10 years on; A partial replication. J Neurol Neurosurg Psychiatry. 2003;74(7):857-62.

[PMID: 12810767]

DOI:10.1136/jnnp.74.7.857

44. Mortimer JA, Van Duijn CM, Chandra V, Fratiglioni L, Graves AB, Heyman A, Jorm AF, Kokmen E, Kondo K, Rocca WA. Head trauma as a risk factor for Alzheimer's disease: A collaborative re-analysis of case-control studies. EURODEM Risk Factors Research Group. Int J Epidemiol. 1991;20(Suppl 2):S28-35. [PMID: 1833351$]$

45. Bramlett HM, Dietrich WD. Neuropathological protection after traumatic brain injury in intact female rats versus males or ovariectomized females. J Neurotrauma. 2001;18(9): 891-900. [PMID: 11565601] DOI:10.1089/089771501750451811

46. Yaffe K, Grady D, Pressman A, Cummings S. Serum estrogen levels, cognitive performance, and risk of cognitive decline in older community women. J Am Geriatr Soc. 1998;46(7):816-21. [PMID: 9670866]

47. Jordan BD, Relkin NR, Ravdin LD, Jacobs AR, Bennett A, Gandy S. Apolipoprotein E epsilon4 associated with chronic traumatic brain injury in boxing. JAMA. 1997;278(2): 136-40. [PMID: 9214529]

DOI:10.1001/jama.278.2.136

48. Newman MF, Croughwell ND, Blumenthal JA, Lowry E, White WD, Spillane W, Davis RD Jr, Glower DD, Smith LR, Mahanna EP. Predictors of cognitive decline after cardiac operation. Ann Thorac Surg. 1995;59(5):1326-30.

[PMID: 7733762]

DOI:10.1016/0003-4975(95)00076-W

49. Nicoll JA, Roberts GW, Graham DI. Apolipoprotein E epsilon 4 allele is associated with deposition of amyloid 
beta-protein following head injury. Nat Med. 1995;1(2): 135-37. [PMID: 7585009]

DOI:10.1038/nm0295-135

50. O’Hara R, Yesavage JA, Kraemer HC, Mauricio M, Friedman LF, Murphy GM Jr. The APOE epsilon4 allele is associated with decline on delayed recall performance in community-dwelling older adults. J Am Geriatr Soc. 1998; 46(12):1493-98. [PMID: 9848808]

51. Tang MX, Maestre G, Tsai WY, Liu XH, Feng L, Chung WY, Chun M, Schofield P, Stern Y, Tycko B, Mayeux R. Effect of age, ethnicity, and head injury on the association between APOE genotypes and Alzheimer's disease. Ann N Y Acad Sci. 1996;802:6-15. [PMID: 8993479] DOI:10.1111/j.1749-6632.1996.tb32593.x

52. Luukinen H, Viramo P, Herala M, Kervinen K, Kesäniemi YA, Savola O, Wingvist S, Jokelainen J, Hillbom M. Fallrelated brain injuries and the risk of dementia in elderly people: A population-based study. Eur J Neurol. 2005;12(2): 86-92. [PMID: 15679695]

DOI:10.1111/j.1468-1331.2004.00953.x

53. Friedman G, Froom P, Sazbon L, Grinblatt I, Shochina M, Tsenter J, Babaey S, Yehuda B, Groswasser Z. Apolipoprotein E-epsilon4 genotype predicts a poor outcome in survivors of traumatic brain injury. Neurology. 1999; 52(2):244-48. [PMID: 9932938]

54. Millar K, Nicoll JA, Thornhill S, Murray GD, Teasdale GM. Long term neuropsychological outcome after head injury: Relation to APOE genotype. J Neurol Neurosurg Psychiatry. 2003;74(8):1047-52. [PMID: 12876232] DOI:10.1136/jnnp.74.8.1047

55. Guo Z, Cupples LA, Kurz A, Auerbach SH, Volicer L, Chui H, Green RC, Sadovnick AD, Duara R, DeCarli C, Johnson K, Go RC, Growdon JH, Haines JL, Kukull WA, Farrer LA. Head injury and the risk of AD in the MIRAGE study. Neurology. 2000;54(6):1316-23. [PMID: 10746604]

56. Jellinger KA, Paulus W, Wrocklage C, Litvan I. Traumatic brain injury as a risk factor for Alzheimer disease. Comparison of two retrospective autopsy cohorts with evaluation of ApoE genotype. BMC Neurol. 2001;1:3. [PMID: 11504565$]$ DOI:10.1186/1471-2377-1-3

57. Jellinger KA, Paulus W, Wrocklage C, Litvan I. Effects of closed traumatic brain injury and genetic factors on the development of Alzheimer's disease. Eur J Neurol. 2001; 8(6):707-10. [PMID: 11784357]

DOI:10.1046/j.1468-1331.2001.00322.x

58. Mauri M, Sinforiani E, Bono G, Cittadella R, Quattrone A, Boller F, Nappi G. Interaction between Apolipoprotein epsilon 4 and traumatic brain injury in patients with Alzheimer's disease and mild cognitive impairment. Funct Neurol. 2006;21(4):223-28. [PMID: 17367583]

59. O’Meara ES, Kukull WA, Sheppard L, Bowen JD, McCormick WC, Teri L, Pfanschmidt M, Thompson JD, Schellen- berg GD, Larson EB. Head injury and risk of Alzheimer's disease by apolipoprotein E genotype. Am J Epidemiol. 1997;146(5):373-84. [PMID: 9290497]

60. Sundström A, Nilsson LG, Cruts M, Adolfsson R, Van Broeckhoven C, Nyberg L. Fatigue before and after mild traumatic brain injury: Pre-post-injury comparisons in relation to Apolipoprotein E. Brain Inj. 2007;21(10):1049-54. [PMID: 17891567] DOI:10.1080/02699050701630367

61. Isoniemi H, Tenovuo O, Portin R, Himanen L, Kairisto V. Outcome of traumatic brain injury after three decadesRelationship to ApoE genotype. J Neurotrauma. 2006;23(11): 1600-1608. [PMID: 17115907] DOI:10.1089/neu.2006.23.1600

62. Gottlieb DJ, DeStefano AL, Foley DJ, Mignot E, Redline S, Givelber RJ, Young T. APOE epsilon4 is associated with obstructive sleep apnea/hypopnea: The Sleep Heart Health Study. Neurology. 2004;63(4):664-68. [PMID: 15326239]

63. Kadotani H, Kadotani T, Young T, Peppard PE, Finn L, Colrain IM, Murphy GM Jr, Mignot E. Association between apolipoprotein $\mathrm{E}$ epsilon4 and sleep-disordered breathing in adults. JAMA. 2001;285(22):2888-90.

[PMID: 11401610]

DOI:10.1001/jama.285.22.2888

64. O’Hara R, Schröder CM, Kraemer HC, Kryla N, Cao C, Miller E, Schatzberg AF, Yesavage JA, Murphy GM Jr. Nocturnal sleep apnea/hypopnea is associated with lower memory performance in APOE epsilon4 carriers. Neurology. 2005;65(4):642-44. [PMID: 16116137] DOI:10.1212/01.wnl.0000173055.75950.bf

65. Gozal D, Capdevila OS, Kheirandish-Gozal L, Crabtree VM. APOE epsilon 4 allele, cognitive dysfunction, and obstructive sleep apnea in children. Neurology. 2007;69(3): 243-49. [PMID: 17636061] DOI:10.1212/01.wnl.0000265818.88703.83

66. Cosentino FI, Bosco P, Drago V, Prestianni G, Lanuzza B, Iero I, Tripodi M, Spada RS, Toscano G, Caraci F, Ferri R. The APOE epsilon4 allele increases the risk of impaired spatial working memory in obstructive sleep apnea. Sleep Med. 2008;9(8):831-39. [PMID: 18083630] DOI:10.1016/j.sleep.2007.10.015

67. Kalra M, Pal P, Kaushal R, Amin RS, Dolan LM, Fitz K, Kumar S, Sheng X, Guha S, Mallik J, Deka R, Chakraborty $\mathrm{R}$. Association of ApoE genetic variants with obstructive sleep apnea in children. Sleep Med. 2008;9(3):260-65. [PMID: 17658295] DOI:10.1016/j.sleep.2007.05.001

68. Bliwise DL, Friedman L, Nekich JC, Yesavage JA. Prediction of outcome in behaviorally based insomnia treatments. J Behav Ther Exp Psychiatry. 1995;26(1):17-23.

[PMID: 7642756] DOI:10.1016/0005-7916(94)00073-U 
69. Dunham CM, Ransom KJ, Flowers LL, Siegal JD, Kohli CM. Cerebral hypoxia in severely brain-injured patients is associated with admission Glasgow Coma Scale score, computed tomographic severity, cerebral perfusion pressure, and survival. J Trauma. 2004;56(3):482-89.

[PMID: 15128117] DOI:10.1097/01.TA.0000114537.52540.95

70. Kemp AM, Stoodley N, Cobley C, Coles L, Kemp KW. Apnoea and brain swelling in non-accidental head injury. Arch Dis Child. 2003;88(6):472-76. [PMID: 12765909] DOI:10.1136/adc.88.6.472

71. Rosner G. Combat hypoxia: The importance of airway management \& oxygenation of the traumatic brain injury patient. JEMS. 2003;28(3):100-117; quiz 118-19. [PMID: 12652281$]$

72. Schwartz DJ, Karatinos G. For individuals with obstructive sleep apnea, institution of CPAP therapy is associated with an amelioration of symptoms of depression which is sustained long term. J Clin Sleep Med. 2007;3(6):631-35. [PMID: 17993046]

73. Chang JJ, Youn TS, Benson D, Mattick H, Andrade N, Harper CR, Moore CB, Madden CJ, Diaz-Arrastia RR. Physiologic and functional outcome correlates of brain tissue hypoxia in traumatic brain injury. Crit Care Med. 2009; 37(1):283-90. [PMID: 19050612] DOI:10.1097/CCM.0b013e318192fbd7

74. Shea TB, Ortiz D, Rogers E. Differential susceptibility of transgenic mice lacking one or both apolipoprotein alleles to folate and vitamin E deprivation. J Alzheimers Dis. 2004;6(3):269-73. [PMID: 15201481]

75. Gozal E, Row BW, Schurr A, Gozal D. Developmental differences in cortical and hippocampal vulnerability to intermittent hypoxia in the rat. Neurosci Lett. 2001;305(3):197-201. [PMID: 11403939] DOI:10.1016/S0304-3940(01)01853-5

76. Rami A, Volkmann T, Agarwal R, Schoninger S, Nürnberger F, Saido TC, Winckler J. Beta2-Adrenergic receptor responsiveness of the calpain-calpastatin system and attenuation of neuronal death in rat hippocampus after transient global ischemia. Neurosci Res. 2003;47(4): 373-82. [PMID: 14630341]

DOI:10.1016/j.neures.2003.07.002

77. Moffat SD, Zonderman AB, Harman SM, Blackman MR, Kawas C, Resnick SM. The relationship between longitudinal declines in dehydroepiandrosterone sulfate concentrations and cognitive performance in older men. Arch Intern Med. 2000;160(14):2193-98. [PMID: 10904463]

DOI:10.1001/archinte.160.14.2193

78. Small GW, Ercoli LM, Silverman DH, Huang SC, Komo S, Bookheimer SY, Lavretsky H, Miller K, Siddarth P, Rasgon NL, Mazziotta JC, Saxena S, Wu HM, Mega MS, Cummings JL, Saunders AM, Pericak-Vance MA, Roses AD,
Barrio JR, Phelps ME. Cerebral metabolic and cognitive decline in persons at genetic risk for Alzheimer's Disease. Proc Natl Acad Sci U S A. 2000;97(11):6037-42.

[PMID: 10811879]

DOI:10.1073/pnas.090106797

79. Soininen H, Partanen K, Pitkänen A, Hallikainen M, Hänninen T, Helisalmi S, Mannermaa A, Ryynänen $M$, Koivisto K, Riekkinen P Sr. Decreased hippocampal volume asymmetry on MRIs in nondemented elderly subjects carrying the apolipoprotein E epsilon 4 allele. Neurology. 1995;45(2):391-92. [PMID: 7854548]

80. Hauri PJ. Sleep hygiene, relaxation therapy, and cognitive interventions. Case studies in insomnia. New York (NY): Plenum Medical Book; 1991. p. 65-84.

81. Stepanski EJ, Wyatt JK. Use of sleep hygiene in the treatment of insomnia. Sleep Med Rev. 2003;7(3):215-25. [PMID: 12927121] DOI:10.1053/smrv.2001.0246

82. Young T, Blustein J, Finn L, Palta M. Sleep-disordered breathing and motor vehicle accidents in a population-based sample of employed adults. Sleep. 1997;20(8):608-13. [PMID: 9351127]

83. Horstmann S, Hess CW, Bassetti C, Gugger M, Mathis J. Sleepiness-related accidents in sleep apnea patients. Sleep. 2000;23(3):383-89. [PMID: 10811382]

84. Ellen RL, Marshall SC, Palayew M, Molnar FJ, Wilson KG, Man-Son-Hing M. Systematic review of motor vehicle crash risk in persons with sleep apnea. J Clin Sleep Med. 2006;2(2):193-200. [PMID: 17557495]

85. Chesnut RM, Carney N, Maynard H, Patterson P, Mann NC, Helfand M. Rehabilitation for traumatic brain injury. Evid Rep Technol Assess (Summ). 1998;2:1-6.

[PMID: 11487799]

86. Robbins J, Redline S, Ervin A, Walsleben JA, Ding J, Nieto FJ. Associations of sleep-disordered breathing and cerebral changes on MRI. J Clin Sleep Med. 2005;1(2):159-65. [PMID: 17561631$]$

87. Webster JB, Bell KR, Hussey JD, Natale TK, Lakshminarayan S. Sleep apnea in adults with traumatic brain injury: A preliminary investigation. Arch Phys Med Rehabil. 2001;82(3):316-21. [PMID: 11245752]

DOI:10.1053/apmr.2001.20840

88. Victor LD. Obstructive sleep apnea. Am Fam Physician. 1999;60(8):2279-86. [PMID: 10593319]

89. Ancoli-Israel S, Kripke DF. Prevalent sleep problems in the aged. Biofeedback Self Regul. 1991;16(4):349-59.

[PMID: 1760457]

DOI:10.1007/BF00999989

90. Kreis P, Kripke DF, Ancoli-Israel S. Sleep apnea: A prospective study. West J Med. 1983;139(2):171-73.

[PMID: 6636727] 
91. Sharafkhaneh A, Giray N, Richardson P, Young T, Hirshkowitz M. Association of psychiatric disorders and sleep apnea in a large cohort. Sleep. 2005;28(11):1405-11. [PMID: 16335330]

92. Mustafa M, Erokwu N, Ebose I, Strohl K. Sleep problems and the risk for sleep disorders in an outpatient veteran population. Sleep Breath. 2005;9(2):57-63. [PMID: 15875229] DOI:10.1007/s11325-005-0016-Z
93. Van Duijn CM, Tanja TA, Haaxma R, Schulte W, Saan RJ, Lameris AJ, Antonides-Hendriks G, Hofman A. Head trauma and the risk of Alzheimer's disease. Am J Epidemiol. 1992; 135(7):775-82. [PMID: 1595677]

Submitted for publication October 14, 2008. Accepted in revised form July 16, 2009. 